\title{
Is it Possible to Improve the Clinical Behaviour of Glass Ionomer Cement Restorations?
}

\author{
Dimitrios Dionysopoulos* \\ Assistant Professor, Department of Operative Dentistry, Faculty of Dentistry, School of Health Sciences, \\ Aristotle University of Thessaloniki, Greece
}

\begin{abstract}
*Corresponding Author: Dimitrios Dionysopoulos, Assistant Professor, Department of Operative Dentistry, Faculty of Dentistry, School of Health Sciences, Aristotle University of Thessaloniki, Greece. Email: ddiondent@gmail.com,ddionys@dent.auth.gr
\end{abstract}

\begin{abstract}
Glass ionomer cements (GICs) are widely used in clinical dentistry due to their advantageous properties. However, they present inferior physical and mechanical properties compared to resin-based restorative materials. In the past, various techniques have been suggested in order to improve the physical and mechanical properties of the conventional GICs, which include radiant heat transfer by use of dental devices such as light emitting diodes (LEDs) or lasers, ultrasonic energy transfer and application of calcium chloride $\left(\mathrm{CaCl}_{2}\right)$ solutions. According to previous in vitro studies the aforementioned clinical treatments may be beneficial for some properties of GICs such as surface hardness, abrasion resistance, water sorption, solubility and compressive strength. However, due to lack of clinical evidence, in vivo studies are necessary to confirm the significance of the laboratory results.
\end{abstract}

\section{EDITORIAL}

Glass ionomer cements (GICs) are widely used in clinical dentistry due to their advantageous properties, such as fluoride ion release and uptake [1], biocompatibility [2], chemical adhesion to dental tissues [3] and similar thermal expansion coefficient to that of dentin [4]. However, they present inferior physical and mechanical properties compared to resin-based restorative materials [5] and this is the reason why they have been limited to use in areas with low masticatory forces and small tooth cavities [6]. More specifically, GICs are sensitive to moisture and their maturing process is slow, which delays the development of their final strength [7] and leads to low initial fracture toughness [8]. Incomplete setting reactions and water contamination during the first stage of GIC setting results in a soft, porous, and fragile cement surface vulnerable to crack formation and, therefore, decreased wear resistance [9].

During setting of GICs an acid-base reaction takes place between a fluoro-alumino-silicate glass and an aqueous solution of polyalkenoic acids. Immediately after mixing, glass particles are attacked by the polyalkenoic acid and as a result metallic cations $\left(\mathrm{Al}^{+3}, \mathrm{Ca}^{+2}\right)$ are released into the solution leading to formation of a silicate gel layer on the glass surface. As the amount of the released cations increases, $\mathrm{pH}$ of the solution also increases, and a greater ionization of carboxylic acids occurs. The gel structure is then formed through weak ionic cross-links and formation of hydrogen bonds (gelation process). As the reaction of the cations with carboxylate groups proceeds the viscosity of the material increases and eventually leads to the hardening of the cement. The final material consists of unreacted glass particles and a poly-salt matrix with cross-link bonds [10].

In previous studies various techniques have been suggested in order to improve the physical and mechanical properties of the conventional GICs, which include radiant heat transfer by use of dental light-curing units such as light emitting diodes (LEDs) [6,11,12] or lasers [13], ultrasonic energy transfer to enhance the motivation and interaction of the reacted components of the GIC $[11,14,15]$ and application of calcium chloride $\left(\mathrm{CaCl}_{2}\right)$ solutions in order to enhance the acidbase reaction between corboxylate groups ($\mathrm{COO}^{-}$) of the polyalkenoic acids and calcium cations $\left(\mathrm{Ca}^{+2}\right)$ of the glass particles of the cement $[16,17]$.

In particular, thermal energy providing by dental LED or laser devices increases surface hardness of the tested GICs by thermo-catalysis. More specifically, radiant heat transfer to the surface of the GIC restorations leads to increased ion 
mobility during the initial stage of setting, decreasing the viscosity of the material which further leads to enhanced reactivity between $\mathrm{Ca}$ ions of the glass particles (powder) and carboxylate groups of the polyalkenoic acids (liquid), resulting to an improved and accelerated setting reaction $[12,18]$. As a result, increase of surface hardness of GICs after the radiant heat treatment expresses the improved formation of polycarboxylate network due to thermo-catalysis of the setting reaction attributed to the provided thermal energy [8]. It is worth noting that induced heat and not output power of a light source is crucial for the thermo-catalysis of the reactions. As a matter of fact, the parameter which is related to the effectiveness of this method is the amount of heat transfer on the surface of the material which depends on thermal emission and duration of the irradiation of the light source $[12,13]$.

There are previous studies that demonstrated increase in surface hardness [15,16], compressive strength [6] and abrasion resistance [19], as well as decrease in solubility and water sorption [20] of various GIC restoratives after radiant heat treatments with LED or laser (diode $-445 \mathrm{~nm}$ ) units. Furthermore, the safety of these treatments on the surface of the restorations (surface morphology and roughness) $[13,20]$ and as regards with the pulp temperature rise $[12,13]$, has been confirmed. On the other hand, it has been reported decrease in fluoride release after the radiant heat treatment due to the improvement of the setting reaction of the GICs and their decrease in solubility $[11,16]$.

Various ways have been suggested that ultrasonic waves may improve the properties of GICs when applied during setting $[6,18,21]$. Adding kinetic energy by using ultrasonic dental scaler to the surface of a GIC the rate of the reaction may increase due to temperature rise.

In a previous study [6] has been observed a temperature increase around $13^{\circ} \mathrm{C}$ for GIC specimens treated with ultrasonic scaler. Nevertheless, in another investigation [22] it was not found significant temperature increase and as a result, the authors concluded that an enhanced setting rate of GICs after ultrasonic treatment is less affected by temperature rise and more by mechanical excitation of the scaler tip itself. It has been postulated that motivation of the scaler enhances the glass particle mixing with polyalkenoic acid chains, resulting in homogenous reaction kinetics. Ultrasonic treatment may have a declustering effect on the glass particles leading to a larger reactive surface area and thus, to a reduced time of setting of GICs
$[6,23]$. It has been reported that high-frequency vibration of the GIC due to the motivation of the scaler tip, enhances the mixing of the glass ionomer components leading to a reduction in the volume and number of voids present in the material [15]. Moreover, the increased temperature of the scaler tip during ultrasonic treatment may cause evaporation of the liquid of the GIC increasing the powder/liquid ratio which leads to higher mechanical properties [6].

The method of improving GIC setting reaction through the supply of Ca cations using a $\mathrm{CaCl}_{2}$ solution is based on the fact that the main setting reaction of GICs is the cross-linking of the carboxylate groups of polyalkenoic acids with the $\mathrm{Al}^{3+}$ and $\mathrm{Ca}^{2+}$ ions released from glass particles. A significant increase in surface hardness of various GICs has been reported when this method is used [16,17,24,25]. Considering that surface hardness of a restorative material is important for its wear resistance, this increase may improve the longevity of the restoration in clinical conditions. It has been found that surface hardness increase is significantly correlated with the concentration of Ca ions on the GIC's surface [17], the immersion time in the $\mathrm{CaCl}_{2}$ solution [24] and the concentration of the solution [24]. A recent study [25] reported that immersion of GIC specimens into $10 \mathrm{ml}$ of a $42.7 \mathrm{wt} \% \mathrm{CaCl}_{2}$ solution (saturated concentration of $\mathrm{CaCl}_{2}$ solution at $20^{\circ} \mathrm{C}$ ) for $60 \mathrm{sec}$ increased surface hardness (5.3 to 7\%), and decreased water sorption (3.3-24.4\%) and solubility (2.2-33.5\%).

In conclusion, many in vitro studies have reported that the aforementioned clinical treatments during the setting of conventional GICs may be advantageous for the longevity of their restorations, attributed to the improvement of the physical and mechanical properties of the materials and the acceleration of the setting reaction. However, due to lack of clinical evidence, in vivo studies are necessary to confirm the significance of the laboratory results.

\section{REFERENCES}

[1] Dionysopoulos D., Koliniotou-Koumpia E., Helvatzoglou-Antoniades M., Kotsanos N., Fluoride release and recharge ability of contemporary fluoride-containing restorative materials and dental adhesives, Dent. Mater. J. 32, 296-304 (2013).

[2] Tamilselvam S., Divyanand M.J., Neelakantan P., Biocompatibility of a conventional glass ionomer, ceramic reinforced glass ionomer, giomer and resin composite to fibroblasts: in vitro study, J. Clin. Pediatr. Dent. 37, 403-406 (2013). 
[3] Nicholson J.W., Adhesion of glass ionomer cements to teeth: a review, Int. J. Adhes. Adhes. 69, 33-38 (2016).

[4] Yan Z., Sidhu S.K., Carrick T.E., McCabe J.F., Response to thermal stimuli of glass ionomer cements, Dent. Mater. 23, 597-600 (2007).

[5] Gu S., Rasimick B.J., Deutsch A.S., Musikant B.L., In vitro evaluation of five core materials, J. Prosthodont. 16, 25-30 (2007).

[6] Kleverlaan C.J., van Duinen R.N.B., Feilzer A.J., Mechanical properties of glass ionomer cements affected by curing methods, Dent. Mater. 20, 45-50 (2004).

[7] de Gee A.J., van Duinen R.N., Werner A., Davidson C.L., Early and long-term wear of conventional and resin-modified glass ionomers, J. Dent. Res. 75, 1613-1619 (1996).

[8] Ilie N., Hickel R., Valceanu A.S., Huth K.C., Fracture toughness of dental restorative materials, Clin. Oral Investig. 16, 489-498 (2012).

[9] Peutzfeldt A., García-Godoy F., Asmussen E., Surface hardness and wear of glass ionomers and compomers, Am. J. Dent. 10, 15-17 (1997).

[10] Nicholson J.W., Chemistry of glass-ionomer cements: a review, Biomaterials 19, 485-494 (1998).

[11] Tolidis K., Dionysopoulos D., Gerasimou P., Sfeikos T., Effect of radiant heat and ultrasound on fluoride release and surface hardness of glass ionomer cements, J. Appl. Biomater. Funct. Mater. 14,. e463-469 (2016).

[12] Gavic L., Gorseta K., Glavina D., Czarnecka B., Nicholson J.W., Heat transfer properties and thermal cure of glass-ionomer dental cements, J. Mater. Sci. Mater. Med. 26, Article 249 (2015).

[13] Dionysopoulos D., Tolidis K., Strakas D., Gerasimou P., Sfeikos T., Gutknecht N., Effect of radiant heat on conventional glass ionomer cements during setting by using blue light diode laser system (445 nm), Lasers Med. Sci. 32, 703709 (2017).

[14] Dehurtevent M., Deveaux E., Hornez J.C., Robberecht L., Tabary N., Chai F., Influence of heat and ultrasonic treatments on the setting and maturation of a glass-ionomer cement, Am J Dent 28, 105-110 (2015).

[15] Towler M.R., Bushby A.J., Billington R.W., Hill R.G., A preliminary comparison of the mechanical properties of chemically cured and ultrasonically cured glass ionomer cements, using nano-indentation techniques, Biomaterials 22, 1401-1406 (2001).
[16] Dionysopoulos D., Tolidis K., Gerasimou P., Sfeikos T., Effect of three clinical curing treatments on fluoride release and surface hardness of glass ionomer cements, Int. J. Periodontics Restorative Dent. 37, e197-e203 (2017).

[17] Shiozawa M, Takahashi H, Iwasaki N., Uo M., Effect of calcium chloride solution immersion on surface hardness of restorative glass ionomer cements, Dent. Mater. J. 32, 828-833 (2013).

[18] de Oliveira B.M.B., Agostini I.E., Baesso M.L., Menezes-Silva R., Borges A.F.S., Navarro M.F.L., Nicholson J.W., Sidhu S.K., Pascotto R.C., Influence of external energy sources on the dynamic setting process of glass-ionomer cements, Dent. Mater. 35, 450-456 (2019).

[19] Dionysopoulos D., Tolidis K., Sfeikos T., Karanasiou C., Parisi X., Evaluation of surface microhardness and abrasion resistance of two dental glass ionomer cements after radiant heat treatment, Adv. Mater. Sci. Eng. Article ID: 5824562 (2017).

[20] Dionysopoulos D., Tolidis K., Strakas D., Gerasimou P., Sfeikos T., Gutknecht N., Effects of blue diode laser (445 $\mathrm{nm}$ ) and LED (430-480 $\mathrm{nm})$ radiant heat treatments on dental glass ionomer cements, Opt. Laser Tech. 99, 249-255 (2018).

[21] Azevedo E.R., Coldebella C.R., Zuanon A.C.C., Effect of ultrasonic excitation on the microtensile bond strength of glass ionomer cements to dentin after different water storage times, Ultrasound Med. Biol. 37, 2133-2138 (2011).

[22] O’Brien T., Shoja-Assadi F., Lea S.C., Burke F.J.T., Palin W.M., Extrinsic energy affect hardness through depth during set of a glassionomer cement, J. Dent. 38, 490-495 (2010).

[23] Towler M.R., Crowley C.M., Hill R.G., Investigation into the ultrasonic setting of glass ionomer cements. Part I: Postulated modalities, J. Mater. Sci. Letters 22, 539-541 (2003).

[24] Shiozawa M., Takahashi H., Iwasaki N., Wada T., Uo M., Effect of immersion time of restorative glass ionomer cements and immersion duration in calcium chloride solution on surface hardness, Dent. Mater. 30, e377-383 (2014).

[25] Dionysopoulos D., Tolidis K., Tortopidis D., Gerasimou P., Sfeikos T., Effect of a calcium chloride solution treatment on physical and mechanical properties of glass ionomer cements, Odontology 106, 429-438 (2018).

Citation: Dimitrios Dionysopoulos. Is it Possible to Improve the Clinical Behaviour of Glass Ionomer Cement Restorations?. ARC Journal of Dental science. 2019; 4(2):6-8. doi:dx.doi.org/ 10.20431/2456-0030. 0402002.

Copyright: (c) 2019 Authors. This is an open-access article distributed under the terms of the Creative Commons Attribution License, which permits unrestricted use, distribution, and reproduction in any medium, provided the original author and source are credited. 